\title{
Supporting Supply Chain Innovation and Sustainability Practices through Knowledge and Innovation Management
}

\begin{abstract}
This paper extends exploratory research on the contribution of knowledge and innovation management (KIM) to innovation and sustainability activities across a number of small to medium size Australian food and beverage exporters in Australia as part of a longitudinal research project. Recent trends in sustainable supply chain management (SSCM) in global supply chains sees a greater focus on achieving more social and transformational forms of sustainability, rather than traditional economic or environmental approaches. Applying a framework of sustainability-oriented innovation, analysis of eight case study organizations revealed that innovation practices across these firms largely reflected an economic focus on sustainability, followed by some activities in the environmental domain. However, more transformative forms of innovation, such as those addressing social/community concerns, were lagging. Although further research is recommended, we offer some propositional speculation on why successful SMEs with a strong reputation for innovation are still driven predominantly by financial considerations.
\end{abstract}

\section{Introduction}

Modern supply chains are regarded as a considerable source of value to contemporary organizations. This value can be significantly enhanced through the strategic management of the supply chain, going beyond the provision of date, goods and services to more sustainable forms of value for a wide range of stakeholders [1] [2]. Indeed, the field of Supply Chain Management [SCM] continues to undergo major changes as increased uncertainty, volatility and risk create many challenges in the global business environment. Under such circumstances, supply chains have become increasingly complex and lengthy. This trend has been accompanied by a recognition of the potential of innovation and strategic SCM practices to create and deliver greater value across a much broader range of stakeholders than might have been the case in the past [3] [4] [5].

The concept of value arising from the strategic management of supply chains has been explored by numerous authors [6] [7] [8]. These works tend to stress that the success of achieving sustainable competitive advantage in SCM is highly dependent on knowledge and the extent to which it is effectively managed [9]. However, the main focus of this body of research has been the creation of value for sustained competitive advantage predominantly in terms of economic performance and measures, with a much lesser focus on environmental or social aspects of value creation within supply chains.

An increasing interest in sustainable development over the past ten to fifteen years has impacted SCM, which can be seen in growing pressure from customers and other stakeholders to support environmental and social sustainability in supply chains. This has led firms to seek new opportunities to support sustainability in their business practices and embed sustainability concerns in their business models and strategy. Indeed, there appears to be significant scope for SCM to support a broad range of sustainability initiatives, especially since research indicates that SCM accounts for the majority of external expenditure in many organizations [10].

This paper seeks to investigate the ways in which knowledge and innovation management (KIM) contributes to sustainability and sustainabilityoriented innovation across a number of small to medium size Australian food and beverage exporters. Driven by a wide range of stakeholders, including consumers, community and government interests, the contemporary push for sustainability across environmental and social dimensions is particularly strong in food supply chains. The organizations in this study are part of an ongoing longitudinal study of supply chain design, innovation and sustainability in food and beverage export from Australia. These firms have been highly successful in global export of their products and gaining a global reputation based on the provenance and quality of their offerings. As a net exporter of food and agribusiness products, Australia currently exports over half of its agricultural products. In Australia, the food and agribusiness export sector was worth $\$ 103.2$ billion in 2017 [11].

Given global concerns about climate change, overconsumption of resources, degradation of the environment and inequity on a social level, the strategic management of knowledge and innovation 
may hold significant potential to create value well beyond the economic realm into iterations of sustainability concerned with environmental and social dimensions. For these firms, a broader interpretation and focus on sustainability, including the development of sustainability oriented innovation practices may be a significant source of competitive advantage [12]. Previous research has shown the potential of KM to support both innovation and sustainability in SCM [13] [14]. By applying a framework of sustainability oriented innovation, which places firm innovation activities on a continuum ranging from 1) compliance and optimization, to 2) transformational and finally to 3 ) system building for greater good, we investigate the ways in which KM supports these activities.

\section{Literature Review}

The globalization of food and agribusiness supply chains over recent decades has led to increased scrutiny and concern relating to sources of food, food quality, provenance and ethical issues related to sourcing [15][16]. The contemporary global food export landscape is characterized by growing demand from consumers and other stakeholders for increased sustainability of food products relating to various issues such as sourcing, traceability, fair trade, food security, less use of plastic packaging and less food waste. These demands could potentially act as a catalyst for organizations involved in food supply chains to develop innovative ways in which to respond.

Modern SCM involves many layers of complexity, including cross-border flows of goods, services, investment, as well as intellectual and human capital that provide challenges at the management level [17]. While it is increasingly clear that the strategic management of supply chains can create value for customers and other stakeholders, the success of creating sustainable competitive advantage in SCM is highly dependent on knowledge and the extent to which it is effectively managed [18].

Past research on SCM has tended to focus on traditional approaches that emphasize financial outcomes without much consideration for environmental or social/community concerns. As an example, a 2011 definition of SCM describes "a set of approaches to integrate supply chain participants so that products are produced and distributed at the right quantities, to the right locations and at the right time to ensure the total cost is minimized and the service level is maximized" [19]. However, a wide range of literature focusing on sustainable supply chain management (SSCM) over the past two decades has challenged traditional SCM definitions and practices linked only to economic performance, thus focusing on sustainability from a combined focus on economic, environmental and social issues [19] [20] [21] [22] [23] [24] [25]. Although many definitions can be found in the literature, Seuring \& Muller [26] define SSCM as "the management of material, information and capital flows as well as cooperation among companies along the supply chain while taking goals from all three dimensions of sustainable development, i.e., economic, environmental and social, into account which are derived from customer and stakeholder requirements".

This shift is indicative of an increasing interest in corporate social responsibility (CSR) as a means of supporting performance across the three 'pillars' of economic, environmental and social issues - the socalled 'triple bottom line' [27]. SSCM thus has a broader scope than traditional SCM approaches and encourages organizations to consider the impact of their business strategy and practices on the environment, consumers, employees, communities and other stakeholders [28]. However, research on SCM is still dominated by a focus on economic performance and bottom line indicators such as cash flow, profit and return on investment [29]. On the other hand, a SSCM approach is much more focused on environmental (green) or social/community issues. Environmentally focused SSCM practices can include green procurement, waste reduction, decisions regarding location, energy use, packaging choices among others. Environmentally focused SSCM practices can include supplier selection, supplier development, logistics options, location decisions, or packaging choices [21] [30] [31] [32]. Finally, SSCM focused on social/community dimensions includes studies relating to corporate governance, social justice, human rights, employee relations, ethics and safety [33] [34]. The social dimension also includes supporting activities or practices in the value chain such as development of new business models that support fair trade and purchasing from minorityowned suppliers [35] [36] [37].

More recent trends concerning sustainability in supply chains go well beyond these boundaries. For instance, Montabon et. al. [38] argue that economic outcomes continue to be prioritized in SSCM approaches at the expense of environmental and social/community concerns, largely due to research in the area of SSCM being underpinned by instrumental logics that fundamentally do not support sustainability in supply chains. In order to counter this dilemma, they advocate the development and application of what they term an 'ecologically dominant logic' with the central premise being that tradeoffs will have to occur 
in order for supply chains to be fully sustainable. When applied, this ecologically dominant logic takes into consideration the environment first, followed by social concerns, then economic performance. It is only when ecologically dominated logic prevails that supply chains will become truly sustainable.

Echoing these sentiments, Markman and Krause [39] argue that no businesses are "truly or fully sustainable" at the present time, and that in order to progress SSCM efforts, a new approach to sustainability is needed. They advocate the adoption of a new paradigm of sustainable practices for supply chains. In this paradigm, environmental concerns are prioritized above all other issues, followed by social concerns, and then finally by the economic dimension. This means that all business activities related to supply chain management must actively contribute to ecological health and wellbeing, maintain ethical standards on behalf of social justice and deliver economic improvements - in that order.

\subsection{Knowledge and Innovation Management and SCM}

The power of knowledge as a strategic resource in modern supply chains is well recognized and beyond dispute [40]. Indeed, the strategic management of knowledge can act as an enabler of SCM in information and knowledge-intensive global environments to capture value and achieve competitive advantage. Previous research on knowledge management (KM) and SCM indicates the various ways in which $\mathrm{KM}$ contributes to SCM capabilities through the application of knowledge processes such as knowledge acquisition, sharing, integration, dissemination, collaboration and innovation [41] [42] [14]. However, there is less literature concerning the role of $\mathrm{KM}$ in supporting SSCM. While some research focuses on the role of knowledge in designing supply chains to incorporate sustainability concerns [22] and in determining supply chain innovation potential to support sustainable development [43], there is a lack of empirical studies in what He et al. [44] term a nascent area of research.

In our previous research we have explored the links between knowledge management and innovation, the development of dynamic capabilities relating to knowledge and innovation management and application of these ideas to SSCM. [45] [22]. Recognizing the inextricable links between knowledge and innovation, we developed a framework of knowledge and innovation management (KIM) as a dynamic capability to capture value from innovation within organizations [45]. KIM can be regarded as a natural extension of the Australian Knowledge Management Standard [6:8] which posits knowledge management as a cross-disciplinary construct. For purposes of this paper, we define KIM as:

...the design, implementation and review of social and technological activities and processes to improve the creation, sharing, dissemination and use of knowledge to support innovation. KIM is concerned with innovation and sharing behaviors, managing complexity and ambiguity through knowledge networks and connections, exploring smart processes, and deploying people-centric technologies across various innovation processes and activities.

The KIM Capability Framework depicts the relationships between the various building blocks of innovation success. Strategic intent coupled with strong leadership drives capabilities such as a strong customer focus and open innovation approaches. A willingness to embrace change and to take calculated risks, coupled with HRM approaches that support innovation, can support sustainability. Effective management of innovation processes, operations, knowledge and technology can combine with a supportive culture to grow systematic forms of innovation capability within organizations. This in turn leads to innovation performance and business success. Ongoing measurement efforts insure that the value accruing from innovation efforts is monitored in order to reinvest in the innovation cycle.

This research is part of a longitudinal study of food and beverage exporters in Australia supported by the Australian Research Council. Previous research relating to this project include a focus on $\mathrm{KM}$ for the design of supply chains [13], as well as the manner in which KM supports sustainability and collaboration in these case organizations [22]. In this paper we now turn our attention to the strategic management of knowledge to support innovation in general, and sustainability oriented innovation in particular within these firms.

\section{Methodology}

This work is underpinned by two complementary theoretical perspectives - the resource based view (RBV) and the knowledge based view (KBV), since both of these frameworks recognize that competitive advantage arises from resources and capabilities at the firm level. In the RBV, knowledge is considered an essential resource within organizations [46] [47], and the generation of value to achieve competitive advantage is dependent on the ways in which firms develop and deploy their knowledge resources and capabilities [48] [49] [50]. Similarly, in the KBV, knowledge is regarded as the penultimate resource, 
where creation, integration and application of knowledge is a foundational attribute of the firm, where knowledge is essential to the development of organizational capabilities to create sustainable competitive advantage [51] [52] [53].

A qualitative cross-case analysis methodology was applied to this study of eight Australian small to medium enterprises (SMEs) in the food and drink sector who have developed successful domestic and overseas export supply chains. These Australian food and beverage producers are all export award winners in the fresh food agri-business area, and are also considered to have developed a high level of innovation capability in order to achieve their current export success. The eight case study companies also claim a strong commitment to sustainability. Details concerning these case study organizations are contained in Table 1.

\begin{tabular}{|c|l|l|}
\hline $\begin{array}{c}\text { Case } \\
\text { code }\end{array}$ & \multicolumn{1}{|c|}{ Business Type } & \multicolumn{1}{|c|}{ Location } \\
\hline 1 & Cherries; apples & Tasmania \\
\hline 2 & $\begin{array}{l}\text { Carrots; onions; other fresh } \\
\text { vegetables }\end{array}$ & Western Australia \\
\hline 3 & Honey and honey products & Tasmania \\
\hline 4 & $\begin{array}{l}\text { Salmon; trout; processed } \\
\text { fish products }\end{array}$ & Tasmania \\
\hline 5 & Whisky; whisky liqueurs & Tasmania \\
\hline 6 & $\begin{array}{l}\text { Fresh truffles; truffle } \\
\text { products }\end{array}$ & Western Australia \\
\hline 7 & Whisky; gin & Tasmania \\
\hline 8 & Abalone & South Australia \\
\hline
\end{tabular}

Table 1. Case study participants

Case studies are well recognized as being a useful means of gaining information in subjective and complex settings where boundaries are often indistinct. Thus this approach is well suited to complex phenomena relating to aspects of knowledge and innovation management in organizations. In terms of reliability, the choice of cases is an important consideration [54]; in this study, the case organizations were selected as part of a purposive sampling methodology to ensure we were looking at strong examples of the phenomena we sought to investigate. This provided a better guarantee that we learned as much as possible from the research. Therefore we sought out a range of Australian companies that had all developed a strong reputation for export success, innovation and a commitment to sustainability. Their success had achieved recognition in the form of Australian federal or state government awards such as 'Exporter of the Year', and these organizations also demonstrated sound KM and innovation practices in their strategy and operations. The main research question underpinning the study concerned the ways in which KIM contributes toward the development of sustainability oriented innovation in the case study organizations.

Multiple case designs yield significantly enhanced results compared with results from a single case research design [54]. However, multiple case designs need to demonstrate structure and focus in analyzing the data and synthesizing the results. Following Miles and Huberman [55] we adopted a "cross-case analysis" approach for enhancing generalizability when investigating complex situations. This cross-case analysis technique increases construct validity, reliability and generalizability of the findings. A content analysis technique analyzed data gathered through in-depth interviews with senior managers or owners, while a multiple cross-case study design tapped into their collective perceptions concerning their respective organization's approach or pathways to the management of their export supply chain [56]. The cross-case analysis identified major themes and subthemes through the use of a case study protocol as recommended by Yin [54], with a set of stem questions guiding participant discussion during the interview.

Initial interviews were conducted with senior managers and other employees in each of the case study organizations. Conducted by the researchers and lasting between 1.5 and 3 hours, the in-depth interviews with senior managers in the case study organizations yielded multiple perspectives concerning various aspects of KIM, particularly in terms of dynamic capabilities and the capacity to enhance innovation efforts.

\begin{tabular}{|c|c|}
\hline $\begin{array}{l}\text { CONTEXT/ } \\
\text { DIMENSION }\end{array}$ & ATTRIBUTES \\
\hline Strategy & $\begin{array}{l}\text { Organizational and management processes aligned } \\
\text { to deliver sustainability }\end{array}$ \\
\hline Process & $\begin{array}{l}\text { The organization of the innovation process to } \\
\text { deliver sustainability; ranges from searching for } \\
\text { new ideas to converting them into products and } \\
\text { services and capturing value from them }\end{array}$ \\
\hline Learning & $\begin{array}{l}\text { Recognizing the value of new knowledge, } \\
\text { assimilating and applying it to support } \\
\text { sustainability }\end{array}$ \\
\hline Linkages & $\begin{array}{l}\text { Internal and external linkages crafted as } \\
\text { opportunities for learning and influencing around } \\
\text { sustainability }\end{array}$ \\
\hline $\begin{array}{l}\text { Innovative } \\
\text { organization }\end{array}$ & $\begin{array}{l}\text { Work organization arrangements that create the } \\
\text { conditions within which SOI can take place (i.e. } \\
\text { enabling structures, communications, training and } \\
\text { development, leadership, reward and recognition } \\
\text { etc.) }\end{array}$ \\
\hline
\end{tabular}

Table 2. Context/Dimensions and Attributes of

Sustainability Oriented Innovation

We applied a framework adapted from Adams et al. [57] to investigate SSCM and innovation practices across various contexts or dimensions, including: 1) 
strategy; 2) process; 3) learning; 4) linkages; and 5) innovation (see Table 2). The Sustainability Oriented Innovation (SOI) framework identifies and maps various innovation attributes at the firm level, with the objective of making organizations more sustainable at the environmental and social levels, as well as in the economic domain. The underlying premise of the framework is that dimensions of innovation to support sustainability can be placed on a continuum ranging from 1) operational to 2) transformative to 3) systems building. At the lowest level of the continuum, operational optimization involves compliance, efficiency gains and incremental improvement activities (doing the same things better). At the second stage, organizational transformation activities include the development of new products, services or business models (doing good by doing new things). At the top end of the continuum, systems building for societal change involves the development of new products, services or business models that can only done in conjunction with others (doing good by doing new things with others) [57].

Specific research questions directed toward participants in the context of KIM included a) the detailed nature of their SSCM practices; b) risk factors affecting sustainability efforts; c) extent of long-term relationships with clients and other stakeholders; d) extent of collaboration with SC partners on development of new technology, products and processes; e) degree of learning and innovation within the company.

\section{Findings and Discussion}

A number of issues were revealed as a result of the interviews with the eight case study companies, and yielded a broad range of information across their approaches to the nature and extent of their SSCM practices, strategic focus, innovation, collaboration and relationships. A summary of the case analyses follows below.

$3 \frac{\text { Case 1 - 'CherryCo' }}{\text { This Tasmanian producer of super premium }}$ cherries, apples and cherry products exports their products to over 20 countries across Europe, Asia and the Middle East, and is considered to be the flagship company for innovation in cherry production processes and export SCM. Ideal climate conditions and strict biosecurity policy and practice in Tasmania means that their cherries are highly sought after in overseas markets, particularly China. Strategy: A 5-year strategic plan with a strong commitment to sustainability underpins the business; part of this strategy involves the appointment of a business development manager to drive the business model and ensure that the strategy cascades through all levels of the business. CherryCo is also strongly committed to supporting
Tasmanian biosecurity policy. This company is considered to be the national leader in cherry production and export, and the business has been family-held for five generations. Seeing a business opportunity, the decision was made to reinvent themselves from $95 \%$ apple producers to $95 \%$ cherry producers over a 15-year period. Process: The company recently completed a multi-million dollar upgrade of their packing shed facility which saw the installation of cutting edge grading technology to ensure high quality standards are met to the highest extent. Other improvements include the establishment of modern high density cherry orchards based on latest knowledge and technology; the orchard is netted to prevent damage from wind, birds and other native animals.. Learning: Five generations of knowledge specific to the business provides a foundation for learning, and the company has employed a number of university qualified experts in business development and cherry production to ensure that the company remains cutting edge. As a result of the expertise brought into the company, they have instituted many innovations to supply chain design, security and traceability as well as strategies to prevent counterfeiting. Linkages: CherryCo enjoys strong, enduring relationships with top tier and long-term customers to whom they guarantee supply. Robust relationships with customers and trade associations are supported by regular travels to markets and customers overseas. However, linkages with customers and other stakeholders do not extend to technology or innovation partnerships. Innovative Organization: there is a commitment to continuous improvement across the organization, but leadership of innovation is concerned with incremental rather than radical forms of innovation within the company.

\section{Case 2 - 'CarrotCo'}

Based in Western Australia, this company's premium product range includes cabbage, carrots, carrot concentrate, celery, onion, pumpkin, potatoes and olive products but by far the majority of the product is carrots and related products that are exported. Strategy: CarrotCo's strategic focus is largely driven by a business model to support growth of overseas export markets on building long term relationships with customers overseas. The business model supports a high degree of vertical integration - they grow, pack and distribute their products as much as possible. Process: Considered to be a major innovator in packaging and processing operations, the company uses advanced technology to quickly cool and safely and efficiently handle, store and distribute its products from the field to the customer. They have also made inroads in technology to support trans-shipping, which is done to the highest possible standard. The company closely guards its IP relating to process innovations. Learning: The company applies both internal expertise and also engages in open innovation with key customers in order to drive process improvements. Linkages: Their focus on maintaining supply consistency and stable pricing, even when markets are volatile, has resulted in successful collaboration with customers overseas. Innovative Organization: Ongoing innovation efforts are focused on areas such as processing, packing, cooling, and quality control. There is some innovation collaboration with customers but this is largely peripheral in nature. However, 
innovation focus is limited to incremental process technology improvements.

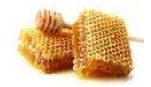

\section{Case 3 - 'HoneyCo'}

This Tasmanian producer of premium honey and related products has accumulated many overseas awards, including World's Best Honey. In addition to premium honey such as leatherwood, the company produces a diversified range of honey-based products such as honey, mead and port; they also are engaged in the shipping of live bees and commercial pollination. Two thirds of their honey is exported, with China their biggest market. Strategy: The business model is underpinned by a focus on investment in technology and innovative practices. Seeking international awards establishes a reputation that grows the business. Process: The company has pioneered the transfer of bees via helicopter in order to gain access to pristine leatherwood forests with minimum ecological impact. Other innovative initiatives include developing new honey extraction techniques and new methods of commercial pollination. They also engage in regular scientific testing of their products to ensure quality. Learning: innovation efforts are supported by a commitment to continuous learning and quality improvement, as well as investment in new product development and process improvements. Linkages: are cornerstones of their success. For a long time the company has recognized the need to develop long-term relationships with partners. As such they collaborate with a number of trusted partners overseas, as well as the Australian agency Austrade for contacts and promotion at trade shows overseas. Stakeholder relationships are a priority. Innovation Organization: innovation efforts focus on technology to support improvements in product quality, processes, traceability, biosecurity and sustainability (such as preserving the environment to support the production of high quality honey such as leatherwood).

\section{Case 4 - 'FishCo'}

Located in Tasmania, this well known producer of premium fresh salmon, trout and other fish products is the largest vertically integrated salmon producer in Australia. Strategy: Fishco's business model emphasizes their commitment to environmental sustainability, quality and innovation. Process: the company has developed a state of the art fish processing facility and an extensive logistics infrastructure in order to ensure quality and freshness of their product as it is exported interstate and overseas. They have also designed open sea pens for salmon in order to mimic conditions in the wild as much as possible. The pens also protect the salmon from predators such as seals in the open ocean. These innovative enclosures ensure that fish are kept in conditions as close to the wild as possible, while at the same time inflicting less ecological damage to inland waters as is the case with traditional fish farming techniques. Learning: Fishco recognizes the need for continual R\&D investment to support innovation. The company grows its expertise both from within and through acquiring specific talent from outside. They also invest heavily in training and learning initiatives for all employees. Linkages: Fishco has developed a number of long standing relationships with its overseas customers, to which senior managers travel regularly for face to face visits; these visits enhance relationships and cross cultural understanding and often lead to ideas for process and/or product improvements. The company considers the community as a most important stakeholder, stressing their commitment to protecting the environment; they are also very proud that they provide employment for many locals who they consider to be part of the Fishco family. Innovative Organization: This company is proud of its reputation for environmental sustainability and their strategy also emphasizes innovation for process and product improvement. They work hard to get this message across, developing a strong brand awareness through 'playing on the back story', emphasizing brand, provenance and their commitment to environmental sustainability. They have even gone to court to protect their sustainability reputation and values against competitors who farm salmon in inland waters and negatively impact ecological stability in local regions. The company has developed many innovations in salmon farming and processing techniques, both radical and incremental. However, innovation efforts stop short of systems building and formal collaboration and relationships to support sustainability.

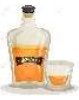

Case 5 - 'Whiskey1Co'

As a winner of many international awards, this distillery located in northern Tasmania has developed an international reputation producing premium niche brand whisky, whiskey liqueurs, vodka and pure distilled water. Strategy: Strategic plans guide the business model, which initially was developed to ensure economic success of the initiative but which now focuses more on protecting aspects of provenance, and protecting the pristine environment from which the product originates. The original company was a small dairy cooperative that could not produce enough volumes of milk to be financially viable. Diversification of the business model saw the company develop the whisky range as an alternative business stream for the future. Process: Most process innovation has been on the development of new products rather than on aspects of distilling. A great deal of effort has gone into building and growing a dedicated Visitors Centre, restaurant and tasting facility at the distillery attracting 40,000 visitors a year, which helps to promote brand awareness and provenance associated with this pristine area of Tasmania. Learning: There is a strong commitment to a philosophy of continuous learning and improvement underpinning business practices. Linkages: The Head Distiller and other senior managers travel overseas regularly to attend whisky fairs and trade shows, acting as ambassadors for Tasmania as a whisky making region and promoting its excellent provenance. Indeed, the company collaborates with other whisky producers located elsewhere in the state of Tasmania to promote the region as one of the best whisky producing regions of the world. An important aspect of developing brand awareness means travelling to meet customers to promote the 'DNA' of the product and its provenance. Over the years the company has developed an excellent overseas distribution network through strong relationships with overseas partners. Innovative Organization: The extent of this business' innovation focus is limited to maintain financial sustainability of the business and supporting 
environmental sustainability in the immediate region where their products are produced.

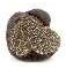

Case 6 - 'TruffleCo'

This producer of fresh truffles and truffle products is based in Western Australia and exports truffles around the world. Branding and marketing are important in building brand awareness through development of a unique Australian provenance story, which allows the company to command a premium price for their products. Strategy: Still in the early stages of growing the business, there is a strong strategic focus on economic development, differentiation through innovative products and processes. Process: In addition to growing fresh truffles in Australian conditions, TruffleCo has been highly innovative in developing a wide range of truffle based and truffle flavored products ranging from honey, aioli, butter, mustard, truffle sauce, salsa, and oils. Indeed the bulk of TruffleCo's products are not fresh truffles, rather they are value added products for various retail and food service markets. Learning: As a small company, much of the learning focus centers on developing knowledge from within. It is hoped that as the company grows, more sources of outside talent and expertise can be brought into the business. Linkages: The business is supported by strong relationships, both up and down the supply chain, with truffle suppliers, customers and distributors. This requires a lot of overseas travel, but such trips often lead to ideas for new products and/or process improvements. Innovative Organization: The strategic focus of the company is focused on growing markets through offering a premium product range, developing bespoke products through application of innovative methods. At the present time there is not a strong innovation focus on environmental or social forms of sustainability; rather, the company's focus is very much on financial stability and growth.

B⿴囗十⺝ $\frac{\text { Case 7 - Whisky2 Co' }}{\text { Established in 1994, this company was the }}$ first successful whisky business in Tasmania. It has now gained a reputation as a producer of one of the best whiskies in the world. Distilled by traditional methods and using only pure Tasmanian ingredients, each barrel is individually tasted and bottled to capture the subtle variations in flavor; this attention to detail has earned them a swag of international awards, including the World's Best Whisky award in London in 2014. Strategy: The business strategy focuses on quality, capacity, sustainability and traceability, and the Head Distiller feels that building a strong and consistent business foundation is of the utmost importance. Process: There is a strong focus on product and process improvement; other than developing a gin product in past years, product developments efforts are focused on the bespoke whisky that forms the backbone of their reputation. Learning: As a small company, much of the learning focus comes from tapping internal expertise of the head distiller and other whisky experts on staff; however, customers are a huge source of feedback that drives learning, especially with regard to flavor, taste and drinkability issues. Linkages: Senior staff spend a lot of time overseas engaging with customers. A great deal of relationship collateral has been developed over the years with experienced partners, traders and distributors in foreign markets who are critical to the success of the export supply chain. Strong relationships with other whisky producers in the Tasmanian region means that they collaborate to promote provenance and support traceability of products from this pristine area. Innovative Organization: The company is more focused on building and maintaining their reputation than mass producing whisky - so for the time being innovation for financial sustainability remains a major emphasis. As the Head Distiller remarked, having spent many years on building brand awareness, they are now prepared to "take more time, have more fun, invent and innovate".

\section{Case 8 - 'AbaloneCo'}

Based in South Australia, this aquaculture company is now the biggest abalone operation in the southern hemisphere. With abalone commanding high prices in overseas markets in Asia and North America, this firm's business model is focused not on short term financial outcomes but more on protecting the pristine environment in which they operate. Strategy: Innovation is key driver of their business model, not only in terms of process innovation but also in terms of environmental protection and sustainability. Process: The company's operations are focused on growing abalone in controlled conditions that replicate natural sea bed environments. This includes using artificial waves to continually cleanse the growing environment. After 18 years of operations, recent innovations are driving plans to triple production output over the next three years. This means that AbaloneCo must ensure that there are multiple growing sites, strict biosecurity measures in place, as well as careful quality control over water, feed and other inputs. Learning: Employees are all charged with responsibility for innovation and much has been achieved through improved knowledge of abalone genetics, energy reductions, as well as other quality and efficiency improvements such as agile packing processes. Linkages: Relationships with customers overseas are well developed and long-term in nature, but at the present time do not contribute to ideation or new technology development. Innovative Organization: There is a clear strategic focus on innovation that promotes core values of innovation, sustainability, traceability, provenance, and technology. Their sustainability focus extends beyond strictly economic considerations to embrace aspects of green sustainability such as protection of the environment in order to ensure that pristine regions in which they grow their abalone are preserved not only for perpetuation of the business, but for the community and generations to come. However, collaboration in a systems building context is not part of their current innovation focus.

Previous research in this longitudinal study [14] indicated that KM plays a major role in supporting SSCM activities in these firms through a number of activities, including development of a strategic focus; reputational promotion and preservation; upholding quality and safety standards and certification; supporting traceability efforts; learning from partners; relationships and communication; as well as 
innovation activities. There were a number of areas in which KM did not appear to make a significant contribution, including joint ideation or development of new technology, products or processes; the technical and logistical integration of supply chain partners; as well as balancing economic, environmental and social goals.

Indeed the ways in which KM supports innovation in these companies appears to be heavily swayed toward financial and to some extent green triple bottom line considerations - areas which are considered to be operational (doing the same things better) and to some extent transformative (doing good by doing new things), according to the continuum of innovation activities depicted in the SOI framework. This most recent study confirms that these best practice exporters who have a reputation for innovation do not demonstrate a strong capacity for balancing economic, environmental and social concerns. Based on the analysis of innovation across dimensions of SOI, we mapped their relative location across the continuum of sustainability-oriented innovation practices, ranging from operational to transformative to systems building (see Figure 1). With the exception of FishCo and AbaloneCo, these firms do not engage in innovation considered to be systems building (doing good by doing good things with others) and therefore potentially able to develop collaborative means by which to challenge existing business models and activities that support higher order form of sustainability. However, with FishCo and AbaloneCo, continuum their activities in the systems building context are very limited at the present time; it will take a lot more before they can be said to be mature and substantial performers in this social sustainability dimension. So it is clear that for the eight case organizations, innovation activities are very much focused on financial sustainability of the business (doing the same things better), followed then by some environmentally driven sustainability commitment (doing good by doing new things).

These results have forced us to take a look at why such successful exporters of food and beverages from pristine environments in Australia are not demonstrating a stronger commitment to environmental and social forms of sustainability in their innovation activities. Given that they are all SMEs, size is perhaps a factor that limits their capacity to go beyond basic elements of financial survival.

Despite knowing the importance of supporting environmental sustainability, most of the SMEs in this study are family owned private firms that are primarily financially oriented. While recognizing that they need the environment in order to stay in business, the core values of these businesses regarding the environment are of secondary concern. These types of firm tend to think and act transactionally where short term ownership and managerial control issues take precedence over more long-term strategic concerns about environmental or social/community sustainability.

Social/community aspects of sustainability are



Figure 1. Mapping case study participants on the SOI 
positioned as being 'nice to have' but certainly are not core to the business model, strategy or innovation activities of family-owned or small business enterprises. Concerns with and decisions regarding environmental and social/community outcomes are mostly a means to an end, yielding a marketing advantage. While collaborative relationships with customers are regarded as strategic and are highly valued and strongly invested in (to drive profitable outcomes), collaboration with suppliers (i.e. machinery, technology, materials and packaging) is very limited and transactional in nature, demonstrating a short-term focus.

In family owned businesses and SMEs, decision making does reflect some concern for triple bottom line sustainability issues across economic, environmental and social/community dimensions; however, the commitment of these firms to environmental and social/community sustainability are limited, with financial considerations always taking precedence to ensure the immediate survival of the business. We also note that the smaller, early stage SMEs appeared less oriented toward sustainability across the three dimensions of sustainability, and were heavily focused on financial survival, growth and investment.

\section{Conclusion}

This paper has extended exploratory research on the contribution of knowledge and innovation management (KIM) to innovation and sustainability activities across a number of small to medium size Australian food and beverage exporters in Australia as part of a longitudinal research project. Recent trends in sustainable supply chain management (SSCM) in global supply chains sees a greater focus on achieving more social and transformational forms of sustainability, rather than traditional economic or environmental approaches. Using a framework of sustainability-oriented innovation, the analysis of eight case study organizations revealed that innovation practices across these firms largely reflected an economic focus on sustainability, followed by some activities in the environmental domain. Disappointingly, more transformative forms of innovation, such as those addressing social/community concerns, were lagging. The SOI framework is a useful tool by which to investigate the nature and extent of innovation activities to support sustainability. This ongoing exploratory research indicates that there is considerable potential for KIM, in conjunction with tools such as the SOI framework to contribute to value and competitive advantage through supporting various SSCM practices, but clearly the challenge lies in applying sophisticated knowledge and innovation management practices to support a higher degree of commitment and involvement in transformative and systems building forms of innovation to support sustainability. Overall there is a lack of substantive research in this area, and so further studies across larger samples, other geographic locations and different types of supply chains may shed further light on the ways in which the management of knowledge and innovation can add value to SSCM.

\section{References}

[1] Hammervoll, T. (2009). Value-Creation Logic in Supply Chain Relationships. Journal of Business-to-Business Marketing, 16(3), pp. 220-241.

[2] Barney, J. B. (2012), Purchasing, Supply Chain Management and Sustained Competitive Advantage: The Relevance of Resourcebased Theory. Journal of Supply Chain Management, 48, pp. 3-6. [3] Melnyk, S.A., Lummus, R.R., Vokurka, R.J., Burns, L. and Sandor, J. (2009). Mapping the future of supply chain management: a Delphi study. International Journal of Production Research, 47(16), pp. 4629-4653.

[4] Von Massow, M. and Canbolat, M. (2014). A strategic decision framework for a value-added supply chain. International Journal of Production Research, 52(7), pp. 1940-1955.

[5] Allesina, S., Azzi, A., Battini, D. and Regattieri, A. (2010). Performance measurement in supply chains: new network analysis and entropic indexes, International Journal of Production Research, 48(8), pp. 2297-2321.

[6] Baldwin, R. and Lopez-Gonzalez, J. (2015). Supply-chain Trade: A Portrait of Global Patterns and Several Testable Hypotheses. The World Economy, 38(11), pp. 1682-1721.

[7] Babin, B. J. and James, K. W. (2010). A brief retrospective and introspective on value. European Business Review, 22(5), pp. 471 478.

[8] Basole, R. C. and Rouse, W.B. (2008). Complexity of Service Value Networks: Conceptualization and Empirical Investigation. IBM Systems Journal, 47(1), pp. 53.

[9] Estampe, D., Lamouri, S., Paris, J. L. and Brahim-Djelloul, S. (2013). A framework for analysing supply chain performance evaluation models. International Journal of Production Economics, 142(2), pp. 247-258.

[10] Tate, W., Ellram, L. and Kirchoff, J. (2010). Corporate Social Responsibility Reports: A Thematic Analysis Related to Supply Chain Management. Journal of Supply Chain Management, 46(1), $19-44$

[11] IBISWorld Statistics on Food Export Industry in Australia. https://www.ibisworld.com.au/industry-trends/market-researchreports/manufacturing/food-product/. Viewed 12 June 2019.

[12] Carter, C.R., and Dale S. Rogers. (2008). A Framework of Sustainable Supply Chain Management: Moving toward New Theory. International Journal of Physical Distribution \& Logistics Management, 38(5), 360 - 387.

[13] Gloet, M. and Samson, D. (2018). The Role of Knowledge Management in Innovative Supply Chain Design. Proceedings of the Hawaii International Conference on System Sciences, January 2018.

[14] Gloet, M. and Samson, D. (2019). Knowledge Management to Support Supply Chain Sustainability and Collaboration Practices. Proceedings of the Hawaii International Conference on System Sciences, January 2019. 
[15] Escanciano, C., \& Leticia Santos-Vijande, M. (2014). Implementation of ISO-22000 in Spain: obstacles and key benefits. British Food Journal, 116(10), 1581-1599.

[16] Wognum, P. N., Bremmers, H., Trienekens, J. H., van der Vorst, J. G., \& Bloemhof, J. M. (2011). Systems for sustainability and transparency of food supply chains-Current status and challenges. Advanced Engineering Informatics, 25(1), 65-76.

[17] Baldwin, R. and Lopez-Gonzalez, J. (2015). Supply-chain Trade: A Portrait of Global Patterns and Several Testable Hypotheses. The World Economy, 38(11), pp. 1682-1721.

[18] Marra, M., Ho, W. and Edwards, J. (2012). "Supply chain knowledge management: A literature review." Expert systems with applications 39 (5), pp. 6103-6110.

[19] Simchi-Levi, D., Kaminsky, P. \& Simchi-Levi, E. (2011). Designing and Managing the Supply Chain. McGraw-Hill, Boston. [20] Pagell, M. and Wu, Z. (2016). Building a more complete theory of sustainable supply chain management using case studies of 10 exemplars. Journal of Supply Chain Management 45(2), 37-56.

[21] Carter, C. R., \& Easton, P. (2011). Sustainable supply chain management: evolution and future directions. International Journal of Physical Distribution \& Logistics Management, 41(1), 46-62.

[22] Chaabane, A., Ramudhin, A. and Paquet, M. (2011). Designing Supply Chains with Sustainability Considerations. Production Planning and Control, 22(8), 727-741.

[23] Ratan, S. R. A., Sekhari, A., Rahman, M., \& Bouras, A. A. (2010). Sustainable Supply Chain Management: State of the Art. SKIMA 2010, 193.

[24] Teuteberg, F., \& Wittstruck, D. (2010). A systematic review of sustainable supply chain management. Multikonferenz Wirtschaftsinformatik 2010, 203.

[25] Markley, M. J., \& Davis, L. (2007). Exploring future competitive advantage through sustainable supply chains. International Journal of Physical Distribution \& Logistics Management, 37(9), 763-774.

[26] Seuring, S., \& Müller, M. (2008). From a literature review to a conceptual framework for sustainable supply chain management. Journal of cleaner production, 16(15), 1699-1710.

[27] Elkington, J. (1998). Partnerships from cannibals with forks: The triple bottom line of 21 st-century business. Environmental Quality Management, 8(1), 37-51.

[28] Peloza, J. and Shang, J. (2011). How can corporate social responsibility activities create value for stakeholders? A systematic review. Journal of the Academy of Marketing Sciences, 39, 117-135. [29] Ratan, S. R. A., Sekhari, A., Rahman, M., \& Bouras, A. A. (2010). Sustainable Supply Chain Management: State of the Art. SKIMA 2010, 193.

[30] Ninlawan, C., Seksan, P., Tossapol, K., \& Pilada, W. (2010, March). The implementation of green supply chain management practices in electronics industry. In Proceedings of the international multiconference of engineers and computer scientists (Vol. 3, pp. 17-19).

[31] Azevedo, S. G., Carvalho, H., \& Machado, V. C. (2011). The influence of green practices on supply chain performance: a case study approach. Transportation research part E: logistics and transportation review, 47(6), 850-871.

[32] Walker, H., \& Brammer, S. (2009). Sustainable procurement in the United Kingdom public sector. Supply Chain Management: An International Journal, 14(2), 128-137.

[33] Sroufe, R. and Drake, M. (2010). Measuring the Social Dimension of the Triple Bottom Line: An

Industry Study. Paper presented at APICS International Conference, 2010.

[34] Closs, D., C. Speier, C. and Meacham, N. (2011). Sustainability to support end-to-end value chains:

the role of supply chain management. Journal of the Academy of Marketing Science, 39(1), 101-

116.

[35] Awaysheh, A. and R. D. Klassen (2010). The impact of supply chain structure on the use of supplier socially responsible practices. International Journal of Operations \& Production Management,

30(12), 1246-1268.

[36] 2010 Prasad, S. and Tata, J. (2010). Micro-Enterprise Supply Chain Management in Developing Countries.

Journal of Advances in Management Research, 7(1), 8-31.

[37] Hall, J and Matos,S. (2010). Incorporating impoverished communities in sustainable supply chains.

International Journal of Physical Distribution and Logistics Management, 40(1/2), 124-147.

[38] Montabon, F., Pagell, M., \& Wu, Z. (2016). Making sustainability sustainable. Journal of Supply Chain Management, 52(2), 11-27.

[39] Markman, G. D., \& Krause, D. (2016). Theory building surrounding sustainable supply chain management: Assessing what we know, exploring where to go. Journal of supply chain management, 52(2), 3-10.

[40] Hult, G.T.M., Ketchen, D., Cavusgil, S.T. \& Calantone, R. (2006). Knowledge as a strategic resource in supply chains, Journal of Operations Management 24, pp. 458-475.

[41] Bhosale, V.A., and Kant, R. (2016). "Metadata analysis of knowledge management in supply chain: investigating the past and predicting the future." Business Process Management Journal 22(1), pp.140-172

[42] Marra, M., Ho, W. and Edwards, J. (2012). "Supply chain knowledge management: A literature review." Expert systems with applications 39 (5), pp. 6103-6110.

[43] Isaksson, R., Johansson, P. and Fischer, K. (2010). Detecting Supply Chin Innovation Potential for Sustainable Development. Journal of Business Ethics, 97(3), pp. 425-442.

[44] He, Q., Gallear, D., Ghobadian, A. and Ramanathan, R. (2019). Managing knowledge in supply chains: a catalyst to triple bottom line sustainability. Production Planning and Control, 30(5-6), pp. 448-463.

[45] Gloet, M. \& Samson, D. (2016). Knowledge and Innovation Management: Developing Dynamic Capabilities to Capture Value from Innovation. Proceedings of the Hawaii International Conference on System Sciences (HICSS), January 2016.

[46] Armstrong, C. and Shimizu, K. (2007), "A Review of Approaches to Empirical Research on the Resource Based View of the Firm", Journal of Management, 33(6), pp. 959-989.

[47] Lockett, A., Thompson, S. and Morgenstern, U. (2009), "The development of the resource-based view of the firm: A critical approach", International Journal of Management Reviews, 11(1), pp. 9-28.

[48] Wernerfelt, B. (1984), The Resource-Based View of the Firm, Strategic Management Journal, 5(2), pp. 171-80.

[49] Barney, J. (1996), "The Resource-Based Theory of the Firm", Organization Science, 7(5), pp. 469-76.

[50] Barney, J. (1991), "Firm Resources and Sustained Competitive Advantage", Journal of Management, 17(1), pp. 99-119.

[51] Grant, R.M. (1996). Toward a knowledge-based theory of the firm. Strategic Management Journal, 17, pp. 109-122.

[52] Conner, K.R. and Prahalad, C.K., 1996. A resource-based theory of the firm: Knowledge versus opportunism. Organization science, 7(5), pp.477-501.

[53] Kogut, B. and Zander, U., 1992. Knowledge of the firm, combinative capabilities, and the replication of technology. Organization science, 3(3), pp.383-397.

[54] Yin, R.K. (2014). Case study research: design and methods, $5^{\text {th }}$ ed., Sage, Thousand Oaks.

[55] Miles, M. B., \& Huberman, A. M. (1994). Qualitative data analysis: An expanded sourcebook. Sage.

[56] Merriam, S. (1998). Qualitative research and case study applications in education. Jossey Bass, San Francisco.

[57] Adams, R., Jeanrenaud, S., Bessant, J. and Denyer, D. (2016). Sustainability-oriented innovation: a systematic review. International Journal of Management Reviews, 18(2), pp. 180-205. 